\title{
From the Editor: Epistemology, Methodology, and the Many Ways of Knowing
}

\author{
Dorothy S. Becvar
}

Published online: 18 February 2009

(C) Springer Science+Business Media, LLC 2009

Gregory Bateson $(1972,1979)$ was instrumental in introducing into the behavioral sciences a focus on epistemology. Examining the general question regarding how we come to know what we know, Bateson also used the term more specifically to refer to the personal worldview or framework according to which each person operates. The latter use is the one with which we marriage and family therapists (MFTs) tend to be particularly concerned as we reflect on our influence on clients and also attempt to understand where they are coming from. At the same time, it often becomes important to consider the general meaning of the term. According to the Oxford English Dictionary (OED, on-line), epistemology refers to the theory or science of the method or grounds of knowledge and answers the general question "What is Knowing and the Known?" or more shortly, "What is Knowledge?" In any professional field, such questions are likely to lead to a consideration of methodology.

The OED defines methodology as referring originally to "the branch of knowledge that deals with method generally or with the methods of a particular discipline or field of study." In subsequent usage the term also has come to refer to, "the study of the direction and implications of empirical research, or of the suitability of the techniques employed in it; (more generally) a method or body of methods used in a particular field of study or activity." 2 In addition to the particular areas of study described in the following pages, this issue also provides an opportunity to consider both the suitability of the techniques employed by researchers and the body of methods used in the MFT field to enhance our knowledge.

Heather Ramey's article, "Modernism, Postmodernism and (Evidence-Based) Practice" offers food for thought regarding the use of various methodologies and their consistency with a particular epistemology. Moving from the more theoretical to the empirical, the next three articles describe the process and outcomes of research using a qualitative methodology. Ronald Chenail, Cynthia Somers, and Joy Benjamin outline their findings from

\footnotetext{
1 http://dictionary.oed.com.cgi/entry_main.50077018?

2 http://dictionary.oed.com.cgi/entry_main.00307811?
}

D. S. Becvar $(\bowtie)$

Saint Louis University, St. Louis, MO, USA

e-mail: becvard@aol.com; becvards@slu.edu 
"A Recursive Frame Qualitative Analysis of MFT Progress Note Tipping Points;" Kami Schwerdtfeger and Karen Wampler consider "Sexual Trauma and Pregnancy: A Qualitative Exploration of Women's Dual Life Experiences;" and Kimberly Flemke focuses on “Triggering Rage: Unresolved Trauma in Women's Lives." In the next article we find a mixed method approach, as Phillip Klever used both quantitative and qualitative methodologies to examine "The Primary Triangle and Variation in Nuclear Family Functioning." Finally, Afshana Haque provides a quantitative analysis in her article on "The Assessment of Marital Adjustment with Muslim Populations: A Reliability Study of The Locke-Wallace Marital Adjustment Test."

As an MFT who espouses a postmodernist/second-order cybernetics perspective (Becvar and Becvar 2009), I do not believe any article necessarily describes the Truth, or if it does, I do not believe that we can know that it does. To me, each offers a story, and all contain some degree of truth that may be useful in different contexts. Further, the more stories we have available and to which we may make recourse, the more our so-called "knowledge" base is enhanced. What is more, as a both/and thinker (and an editor) it pleases me to see as well as receive articles that represent a variety of epistemological and methodological positions, indicating an important aspect of our field. Indeed, this speaks of the many ways of knowing, all of which may be understood as having some validity.

\section{References}

Bateson, G. (1972). Steps to an ecology of mind. New York: Ballantine.

Bateson, G. (1979). Mind and nature: A necessary unity. New York: E. P. Dutton.

Becvar, D. S., \& Becvar, R. J. (2009). Family therapy: A systemic integration (7th ed.). Boston: Allyn \& Bacon. 